\title{
Tease or threat? Judging social interactions from bodily expressions
}

Citation for published version (APA):

Sinke, C. B. A., Sorger, B., Goebel, R., \& de Gelder, B. (2010). Tease or threat? Judging social interactions from bodily expressions. Neuroimage, 49(2), 1717-1727. https://doi.org/10.1016/j.neuroimage.2009.09.065

Document status and date:

Published: 15/01/2010

DOI:

10.1016/j.neuroimage.2009.09.065

Document Version:

Publisher's PDF, also known as Version of record

Document license:

Taverne

Please check the document version of this publication:

- A submitted manuscript is the version of the article upon submission and before peer-review. There can be important differences between the submitted version and the official published version of record.

People interested in the research are advised to contact the author for the final version of the publication, or visit the DOI to the publisher's website.

- The final author version and the galley proof are versions of the publication after peer review.

- The final published version features the final layout of the paper including the volume, issue and page numbers.

Link to publication

\footnotetext{
General rights rights.

- You may freely distribute the URL identifying the publication in the public portal. please follow below link for the End User Agreement:

www.umlib.nl/taverne-license

Take down policy

If you believe that this document breaches copyright please contact us at:

repository@maastrichtuniversity.nl

providing details and we will investigate your claim.
}

Copyright and moral rights for the publications made accessible in the public portal are retained by the authors and/or other copyright owners and it is a condition of accessing publications that users recognise and abide by the legal requirements associated with these

- Users may download and print one copy of any publication from the public portal for the purpose of private study or research.

- You may not further distribute the material or use it for any profit-making activity or commercial gain

If the publication is distributed under the terms of Article $25 \mathrm{fa}$ of the Dutch Copyright Act, indicated by the "Taverne" license above, 


\title{
Tease or threat? Judging social interactions from bodily expressions
}

\author{
C.B.A. Sinke ${ }^{\mathrm{a}, \mathrm{b}}$, B. Sorger ${ }^{\mathrm{b}}$, R. Goebel ${ }^{\mathrm{b}}$, B. de Gelder ${ }^{\mathrm{a}, \mathrm{c}, *}$ \\ a Cognitive and Affective Neurosciences Laboratory, Tilburg University, Tilburg, The Netherlands \\ b Department of Cognitive Neuroscience, Maastricht University, Maastricht, The Netherlands \\ ${ }^{c}$ Martinos Center for Biomedical Imaging, Massachusetts General Hospital, Harvard Medical School, Charlestown, MA, USA
}

\section{A R T I C L E I N F O}

\section{Article history:}

Received 24 June 2009

Revised 25 September 2009

Accepted 28 September 2009

Available online 3 October 2009

\section{Keywords:}

Emotion

Bodily expressions

Threat

fMRI

Social interaction

Attention

\begin{abstract}
A B S T R A C T
We casually observe many interactions that do not really concern us. Yet sometimes we need to be able to rapidly appraise whether an interaction between two people represents a real threat for one of them rather than an innocent tease. Using functional magnetic resonance imaging, we investigated whether small differences in the body language of two interacting people are picked up by the brain even if observers are performing an unrelated task. Fourteen participants were scanned while watching 3-s movies (192 trials and 96 scrambles) showing a male person either threatening or teasing a female one. In one task condition, observers categorized the interaction as threatening or teasing, and in the other, they monitored randomly appearing dots and categorized the color. Our results clearly show that right amygdala responds more to threatening than to teasing situations irrespective of the observers' task. When observers' attention is not explicitly directed to the situation, this heightened amygdala activation goes together with increased activity in body sensitive regions in fusiform gyrus, extrastriate body area-human motion complex and superior temporal sulcus and is associated with a better behavioral performance of the participants during threatening situations. In addition, regions involved in action observation (inferior frontal gyrus, temporoparietal junction, and inferior parietal lobe) and preparation (premotor, putamen) show increased activation for threat videos. Also regions involved in processing moral violations (temporoparietal junction, hypothalamus) reacted selectively to the threatening interactions. Taken together, our results show which brain regions react selectively to witnessing a threatening interaction even if the situation is not attended because the observers perform an unrelated task.
\end{abstract}

(C) 2009 Elsevier Inc. All rights reserved.
When walking along busy streets, we are often surrounded by people engaged in intense interactions. The casual observer witnesses these without paying much attention. Yet sometimes a scene between two people that looks like a playful tease may in fact be an aggression. Rapid discrimination of whether we witness another person being teased or aggressed will prompt an observer either not to get involved or to be of assistance to the potential victim. Our goal was to find out whether observers pick up small differences in the body language of two interacting people allowing them to tell whether their interaction is just about teasing or represents a real menace, and how this is reflected in condition specific brain activations.

Research on bodily expressions is a relatively new field in cognitive neuroscience. Available literature shows that fusiform gyrus (FG) and amygdala (AMG) play an important role in perceiving bodily expressions, as well as other areas that are closely related to emotional processes like orbitofrontal cortex (OFC) and insula

\footnotetext{
* Corresponding author. Cognitive and Affective Neurosciences Laboratory, Tilburg University, 5000 LE Tilburg, The Netherlands.

E-mail address: B.deGelder@uvt.nl (B. de Gelder).
}

(Hadjikhani and de Gelder, 2003; de Gelder et al., 2004) (for an overview, see de Gelder, 2006). This emotion-related activation cooccurs with activation of areas involved in representation of action and movement including the inferior frontal gyrus (IFG), supplementary motor area (SMA), caudate nucleus, and putamen. Additionally, activation found in areas related to stimulus detection/ orientation (superior colliculus (SC) and pulvinar) appears compatible with models postulating a rapid, automatic route for fear detection (LeDoux, 1992).

Some recent studies of bodily expressions have used dynamic stimuli and have proven useful for better understanding the respective contribution of action-related and emotion components. For example, a study by Grosbras and Paus (2006) showed that video clips of angry hands trigger activations that largely overlap with those reported for facial expressions in the FG. Two eventrelated functional magnetic resonance imaging (fMRI) studies have been performed with fearful and angry whole body expressions in movies (Grèzes et al., 2007; Pichon et al., 2007). The movies showed someone opening a door in either a fearful/angry way or a neutral way and the role of the dynamics was clarified when activations were compared with those for static pictures. Both studies found an interaction between the emotion and movement 
in the superior temporal sulci (STS) and right premotor cortex (PM) with more activation for fear/anger than for neutral, but only when dynamic information was present. These results indicate that these areas probably represent the perceived emotional action.

All studies mentioned so far use bodily expressions shown by a single actor, but our everyday life evolves around observing and participating in interactions including multiple agents. To address this novel issue, we selected a familiar situation involving two people and showing a male actor either teasing or threatening a female. Our first prediction was that observing a threatening compared to a teasing situation will trigger more AMG responses in the observer. Secondly, related to this, previous investigations of the role of attention have suggested that emotional signals are processed even when attention is engaged elsewhere because threat signals are perceived automatically and independently of attention (Dolan and Vuilleumier, 2003; Tamietto et al., 2007). But this does not exclude that availability of attentional resources influences AMG activity (Pessoa et al., 2005). Here we predicted that even when involved in an attention demanding task, which may reduce the available cortical resources, observing a threat interaction still triggers AMG more than a teasing situation.

A third prediction involves the role of body processing areas in FG, lateral occipitotemporal cortex (extrastriate body area (EBA)-human motion complex (hMT+/V5)) and STS. It is presently not known whether these areas are involved in processing interactions, and if so, whether they react differentially to the type of interaction observed. Since FG and AMG have consistently been found in many face and body studies (Adolphs, 2003; Hadjikhani and de Gelder, 2003), we also expected this area to be more activated for threat than tease in general. Plus, we expected that when AMG reacts to the threat in the attention demanding task, this information will be passed through to FG, leading also to more activation for threat than tease in this condition. Additionally, we expected EBA-hMT+/V5 and STS to be more responsive to threat than tease in general, a result which was found with angry and fearful body movements (Grèzes et al., 2007; Pichon et al., 2007).

Furthermore, we explored the relation between emotion and action representation. Observing the interacting bodies will lead to an imitative response tendency - as behavioral studies have found (Brass et al., 2001) - and possibly trigger regions involved in action representation and preparation. These regions - which include PM, inferior frontal gyrus (IFG; Brodmann's areas (BA) 44/ 45), rostral inferior parietal lobe (IPL), and STS - are likely to be more responsive when the actions are threatening as found by previous studies (de Gelder et al., 2004; Pichon et al., 2007; Grèzes et al., 2007). This may even be the case, and it might even be the case when the threat is not directly aimed towards the observer because a defensive reaction might still be necessary in case the attacker decides to also turn against you. Also, it seems adaptive to have this mechanism operational automatically even if we engage in an attention demanding task (Brass et al., 2001).

Finally, in contrast with almost all previous studies exposing participants to affective stimuli, the role of our participants is clearly defined as being a witness of an interaction of which they are not part. Like in everyday life, the observer may more or less empathize with the victim or be more or less indifferent to what goes on around him. In line with this, we expected areas involved in moral cognition - including anterior temporal pole (TP), medial prefrontal cortex (PFC), and OFC (Moll et al., 2008; Zahn et al., 2008) - to be activated during the movies where attention is explicitly on the situation. Furthermore, when this situation is threatening, it may activate PFC and OFC even more, as well as insula, hypothalamus and temporoparietal junction (TPJ) as found in studies for moral violations (Berthoz et al., 2002; Moll et al., 2008; Zahn et al., 2008).

\section{Methods}

\section{Participants}

Fourteen healthy volunteers (five males; $23.6 \pm 5.1$ years; all righthanded) participated in this experiment after providing written informed consent. All participants had normal or corrected-to-normal vision. The study was performed in accordance to the Declaration of Helsinki and was approved by the local medical ethical committee.

\section{Materials}

Fourteen students (seven males) of the University of Tilburg were filmed while they were engaged into a social interaction which always involved one male and one female. The male actor was trying to grab the handbag of the female actor and did so either in a playful way or aggressively. In the latter case, the male expressed anger and the female expressed fear.

The raw footage was edited into 3 -s movies $(484 \times 504$ pixels; 25 frames/second; 209 kbps data rate; 24 -bit sample size; compressed by Indeo video $5 ; 11.5 \times 12 \mathrm{~cm}$ on screen) using Ulead VideoStudio (version 10) and processed with Adobe After Effects (version 6). Editing comprised blurring of the faces, converting the videos into black/ white, and, in a later stage, putting a colored dot in three frames $(40 \mathrm{~ms}$ visual angle $=0.3^{\circ}$ ) of each movie. Furthermore, a scrambled version of each movie was made by performing a Fourier transformation in Matlab (version 7.4) whereby phases of each RVB layer were scrambled. The scrambling has been kept constant for each movie so that we did not induce any differential scrambling between layers and frames.

The edited movies were validated by a group of different participants using a forced choice response (threatening vs. teasing) and they were also rated on emotional intensity. For the final experiment, 12 actor combinations which had the best recognition rates ( mean $=87.7 \%, S D=13.29$ ) were selected. Each actor combination appeared in every stimulus condition. However, two different stimuli sets were created so that one and the same male actor was always either an aggressor or a teaser for one subject, in order to make the situation more realistic.

\section{Design and procedure}

A slow event-related design was used with enough time between the separate movies for the BOLD response to largely return to baseline. After each 3-s movie, an answer screen appeared for $2 \mathrm{~s}$, followed by a fixation interval of $11 \mathrm{~s}$ (see Fig. 1).

Every session comprised four functional runs. There was one task per run in order to prevent confusion to the participants. During the color naming task, participants had to ignore what happened in the movies and pay attention to three colored dots that appeared during those movies. The dots could be blue or yellow and the participants had to make a forced choice of whether those dots were of the same or of different colors. The dots always appeared somewhere on the bodies in order to minimize the shifts in spatial attention across conditions. During the emotion naming task, participants had to pay attention to the actors in the movies and they had to make a forced choice of whether the situation was threatening or teasing. On the following answer screen, the response alternatives appeared randomly left or right of the fixation cross so that participants had to withhold their response until after the movie in order to avoid motor anticipation related effects.

Stimuli were presented using Presentation software (Neurobehavioral Systems, Inc, version 11.0). The participants had to perform both tasks twice in two runs each, with an anatomical scan in the middle.

A total of 288 trials (including 96 scrambled videos) were presented. All stimuli (12 threatening, 12 teasing videos) were presented 
a

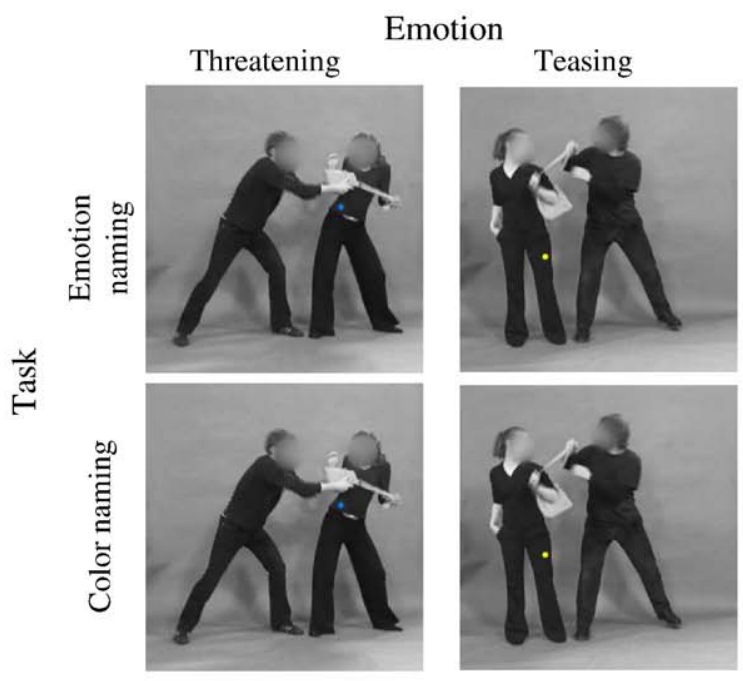

b

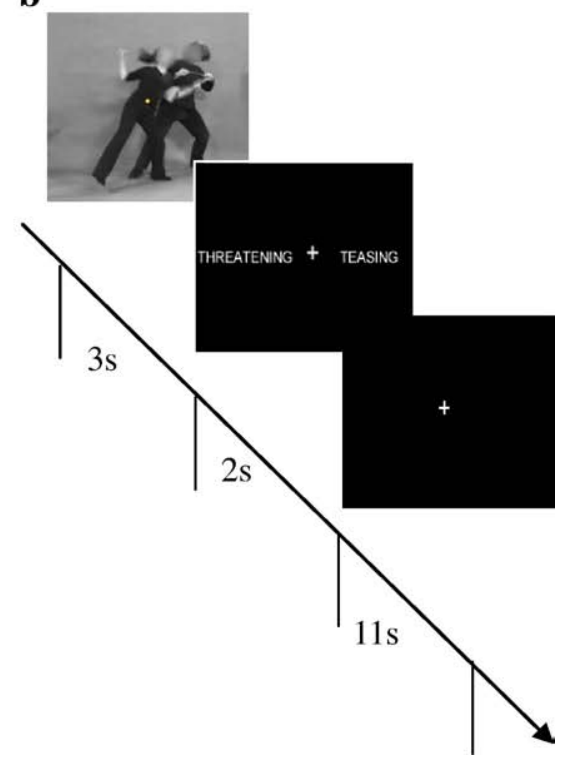

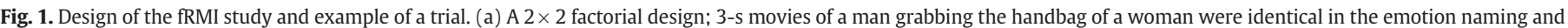

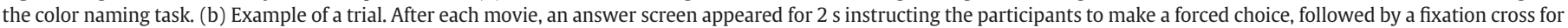
$11 \mathrm{~s}$ until the start of the next movie.

twice per run and the scrambled movies only once. Each functional run contained 72 trials. Every stimulus was synchronized to a trigger from the scanner, so each movie started at the same time as a new scan volume.

All stimuli were generated by a PC and projected onto a frosted screen located at the end of the scanner bore (at the side of the participants' head) with a liquid crystal display (LCD) projector (PLCXT11-16, Sanyo North America Corporation, San Diego, USA). The participants viewed the stimuli via a mirror mounted to the head coil at an angle of $\pm 45^{\circ}$.

\section{fMRI data acquisition}

The MRI unit used was a commercial head scanner with a magnetic field strength of $3 \mathrm{~T}$ (Siemens Allegra, AG, Erlangen, Germany) provided with a standard quadrature birdcage head coil. Foam padding placed around the head was used to minimize movement and the participants were provided with ear plugs to reduce the scanner noise.

In each session, after a first quick nine-slice localizer for orientation, a three-dimensional (3D) T1-weighted data set was scanned using parameters from the Alzheimer's Disease Neuroimaging Initiative (ADNI) encompassing the whole brain (scan parameters: repetition time $(\mathrm{TR})=2250 \mathrm{~ms}$, echo time $(\mathrm{TE})=2.4 \mathrm{~ms}$, flip angle $(\mathrm{FA})=9^{\circ}$, field of view $(\mathrm{FOV})=256 \times 256 \mathrm{~mm}^{2}$, matrix size $=$ $256 \times 256$, number of slices $=192$, slice thickness $=1 \mathrm{~mm}$, no gap, total scan time $=8$ min $5 \mathrm{~s}$ ).

The scan parameters of the functional sequence used were: $\mathrm{TR}=2000 \mathrm{~ms}, \mathrm{TE}=30 \mathrm{~ms}, \mathrm{FA}=90^{\circ}$, matrix size $=64 \times 64, \mathrm{FOV}=$ $224 \times 224 \mathrm{~mm}^{2}$, slice order $=$ descending-interleaved, slice thickness $=3.5 \mathrm{~mm}$ (no gap), number of volumes $=583$ for the color naming runs (total scan time $=19 \min 26 \mathrm{~s}$ ), 559 for the emotion naming runs (total scan time $=18 \mathrm{~min} 38 \mathrm{~s}$ ). The emotion naming runs were a bit shorter than the color naming runs because the scrambled movies were not followed by an answer screen in the former.

\section{Behavioral data analysis}

To test whether performance on the emotion vs. color naming task was different for the threatening vs. teasing movies, a planned comparison was performed with a paired-samples $t$-test in SPSS (version 15.0 for Windows). Also, a repeated-measures univariate analysis of variance (ANOVA) was performed with two factors (emotion - task) and two levels (threatening/teasing - emotion naming/color naming) to see whether there was a difference in performance between the two tasks.

\section{fMRI data analysis}

For the fMRI data analysis, BrainVoyager QX (version 1.9 Brain Innovation, Maastricht, the Netherlands) was used. A number of preprocessing steps were performed on the functional data. These included incremental linear trend removal to eliminate scannerrelated signal drifts; temporal high-pass filtering to remove temporal frequencies lower than 3 cycles per run; and a rigid-body algorithm which rotates and translates each functional volume in 3D space in order to correct for small head movements in between scans. For the group ANOVA on the volume and the surface, the data was spatially smoothed with a $4 \mathrm{~mm}$ Gaussian kernel. To enable the comparison between participants, all anatomical as well as functional volumes were spatially normalized into Talairach space. The first two scans per run were excluded from the analysis to permit T1 equilibration effects. The 3D T1-weighted scans were used to overlay the statistical maps on for anatomical orientation.

At single-subject level, fixed-effects whole-brain ANOVAs were performed using a regression model consisting of the eight predictors corresponding to the particular experimental conditions (threatening and teasing expressions of the actors in the two task conditions and the scrambled versions of the four stimulus conditions) plus a ninth for the response period. The predictor time courses used were generated on the basis of a linear model of the relation between neural activation and hemodynamic response. Furthermore, regions of interest (ROIs) were localized by contrasting all movies $v s$. their scrambled counterparts using a conjunction analysis approach. This way, we aimed to define the following regions per subject: FG, EBA$\mathrm{hMT}+/ \mathrm{V} 5$, and STS. They were chosen with relatively liberal uncorrected criterion (minimum $p<.05,200-600$ voxels). The AMG was anatomically defined. beta-Values from the ROIs were extracted from BrainVoyager into SPSS (Version 15.0) in order to perform a 
random-effects ANOVA to look for main effects of emotion and task and for interaction effects. In case of an interaction, paired-samples ttests were performed to look specifically at both tasks and both emotions separately.

At group level, a single-subject ROI-based group ANOVA with two within-participants factors (emotion $\times$ task) with two levels (threatening/teasing - emotion naming/color naming) had been performed. Secondly, a whole-brain random-effects ANOVA with the same factors was performed to exploratory look for the main effects of emotion and task and for interaction effects. The resulting volume maps per contrast were subjected to a cluster-level statistical threshold analysis in order to correct for multiple comparisons (Forman et al., 1995; Goebel et al., 2006). Additionally, after segmenting the grey from the white matter from each individual brain, a cortex-based alignment (CBA) was performed with all brains separately for the left and right hemisphere to reduce individual macro-anatomical differences between subjects. While the algorithm uses curvature information as its cost function, it effectively aligns homologue gyri and sulci across subjects. One person was excluded from this analysis since the anatomical scan was too blurry for segmentation due to extensive head motion. An average segmented (surface-based) brain representation was created after alignment on which a random-effects ANOVA had been performed with the same predictors as before. Also with the resulting volume maps, cluster-level statistical threshold analyses had been performed.

For the analysis within the ROIs, a threshold of $p<.05$ was used. The whole-brain analyses were corrected for cluster size. Only the group results are reported.

\section{Results}

\section{Behavioral results}

Threatening situations were well recognized as shown in the average recognition rates during the emotion naming task (mean $=$ $83.9 \%, \mathrm{SD}=11.15$ ) and participants also performed well in the color naming task (mean $=90.8 \%, S D=8.32$ ) (see Fig. 2). A repeatedmeasures ANOVA showed that there was an emotion effect $(F(1,10)=$ $5.455, p=.042, \eta \mathrm{p} 2=.353)$ as well as a task effect $(F(1,10)=13.875$, $p=.004, \eta \mathrm{p} 2=.581)$ indicating that recognition rates were highest in the color naming condition and for threatening movies.

Although there was no interaction, the planned comparison showed that participants performed the color naming task better when there was a threatening situation in contrast to a teasing one $(t(12)=3.051, p=.010, d=1.056)$.

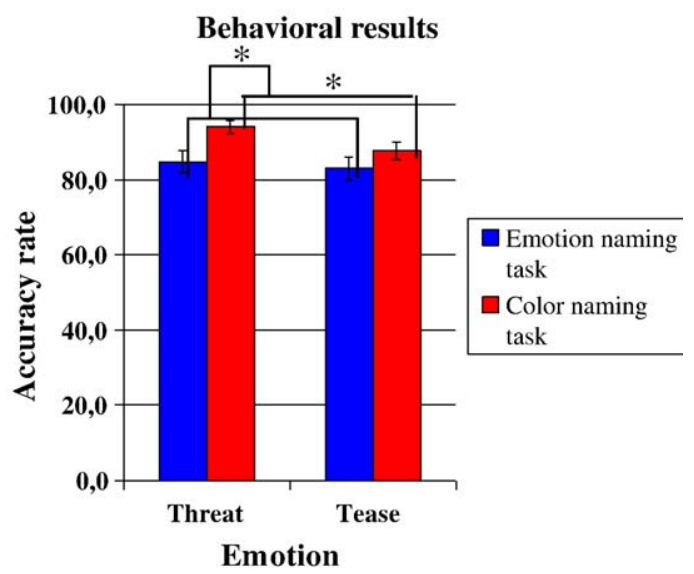

Fig. 2. Behavioral results. Mean accuracy rates for threatening and teasing movies during both tasks. Participants performed the color naming task better than the emotion naming task, and they performed the color naming task better during threatening than teasing movies.
Table 1

Average Talairach coordinates for all ROIs as found with the localizer.

\begin{tabular}{llrrr}
\hline Region & Hemisphere & \multicolumn{1}{l}{$x(\mathrm{SD})$} & \multicolumn{1}{l}{$z$} \\
\hline EBA & $\mathrm{L}$ & $-46(3.8)$ & $-68(5.3)$ & $4(3.8)$ \\
EBA & $\mathrm{R}$ & $45(3.0)$ & $-65(3.6)$ & $1(4.7)$ \\
FG & $\mathrm{L}$ & $-39(4.6)$ & $-44(6.8)$ & $-15(3.5)$ \\
FG & $\mathrm{R}$ & $37(2.9)$ & $-43(7.0)$ & $-13(4.5)$ \\
STS & $\mathrm{L}$ & $-50(5.4)$ & $-41(7.8)$ & $17(7.2)$ \\
STS & $\mathrm{R}$ & $50(4.0)$ & $-38(7.7)$ & $14(4.3)$ \\
AMG & $\mathrm{L}$ & $-18(4.0)$ & $-6(4.3)$ & $-16(1.4)$ \\
AMG & $\mathrm{R}$ & $18(2.4)$ & $-5(3.6)$ & $-16(1.7)$ \\
\hline
\end{tabular}

Left STS was located in only 6 subjects, right STS was located in 12 subjects.

\section{fMRI results}

\section{ROI analysis}

It was possible to locate in almost every subject the ROIs we were interested in. However, it was only possible to locate left STS in less than half of the participants, which is not surprising since more studies found this right hemisphere STS lateralization for biological motion perception (Bonda et al., 1996; Beauchamp et al., 2003). Table 1 shows the average Talairach coordinates per ROI and Table 2 shows the individual Talairach coordinates for the main regions.

An emotion effect was found in right AMG, with more activation for threatening than teasing interactions $(F(1,13)=6.024, p=.029, \eta$ $\mathrm{p} 2=.32$ ). In left AMG no effects were found (see Fig. 3 ).

Left FG $(F(1,13)=6.453, p=.025, \eta \mathrm{p} 2=.33)$ showed an interaction effect between emotion and task (see Fig. 4). Right FG showed a trend towards interaction $(F(1,13)=3.942, p=.069, \eta \mathrm{p} 2=.23)$ and a main effect for task with more activation during the emotion than

Table 2

Single-subject Talairach coordinates for left fusiform gyrus (FG) and right posterior superior temporal sulcus (STS) as found with the contrast movies vs. scrambles.

\begin{tabular}{|c|c|c|c|c|c|c|c|c|c|}
\hline \multicolumn{5}{|l|}{ Left FG } & \multicolumn{5}{|c|}{ Right STS } \\
\hline Subject & $x$ & $y$ & $z$ & Voxels & Subject & $x$ & $y$ & $z$ & Voxels \\
\hline 1 & -32 & -48 & -13 & 222 & 1 & 52 & -37 & 10 & 1010 \\
\hline 2 & -33 & -41 & -21 & 390 & 2 & 51 & -34 & 17 & 151 \\
\hline 3 & -42 & -62 & -13 & 507 & 3 & 50 & -49 & 16 & 758 \\
\hline 4 & -41 & -39 & -14 & 440 & 4 & Not & localiza & & \\
\hline 5 & -39 & -39 & -17 & 275 & 5 & Not & localiza & & \\
\hline 6 & -31 & -37 & -19 & 279 & 6 & 52 & -47 & 22 & 992 \\
\hline 7 & -42 & -44 & -13 & 209 & 7 & 51 & -30 & 8 & 627 \\
\hline 8 & -36 & -47 & -9 & 391 & 8 & 58 & -22 & 15 & 251 \\
\hline 9 & -43 & -38 & -14 & 325 & 9 & 50 & -19 & -5 & 674 \\
\hline 10 & -47 & -41 & -14 & 218 & 10 & 50 & -40 & 10 & 126 \\
\hline 11 & -37 & -50 & -18 & 357 & 11 & 44 & -34 & 9 & 138 \\
\hline 12 & -37 & -42 & -17 & 390 & 12 & 53 & -37 & 19 & 396 \\
\hline 13 & -40 & -42 & -9 & 187 & 13 & 50 & -37 & 15 & 194 \\
\hline 14 & -42 & -51 & -12 & 170 & 14 & 43 & -44 & 17 & 471 \\
\hline \multicolumn{10}{|c|}{ Right AMG } \\
\hline Subject & $x$ & $y$ & $z$ & Voxels & & & & & \\
\hline 1 & 15 & -5 & -16 & 285 & & & & & \\
\hline 2 & 19 & -4 & -15 & 514 & & & & & \\
\hline 3 & 16 & -4 & -16 & 333 & & & & & \\
\hline 4 & 18 & -3 & -19 & 263 & & & & & \\
\hline 5 & 17 & 0 & -17 & 297 & & & & & \\
\hline 6 & 16 & -3 & -15 & 352 & & & & & \\
\hline 7 & 17 & -5 & -16 & 314 & & & & & \\
\hline 8 & 17 & -5 & -13 & 282 & & & & & \\
\hline 9 & 16 & -3 & -15 & 307 & & & & & \\
\hline 10 & 20 & -8 & -12 & 345 & & & & & \\
\hline 11 & 17 & 0 & -17 & 421 & & & & & \\
\hline 12 & 20 & -5 & -17 & 209 & & & & & \\
\hline 13 & 18 & -10 & 17 & 379 & & & & & \\
\hline 14 & 24 & -12 & 15 & 395 & & & & & \\
\hline
\end{tabular}

Right amygdala (AMG) was found anatomically. 


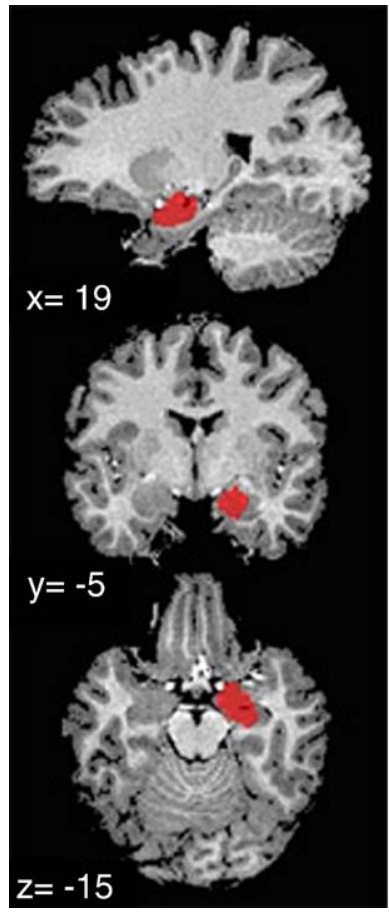

\section{right AMG}

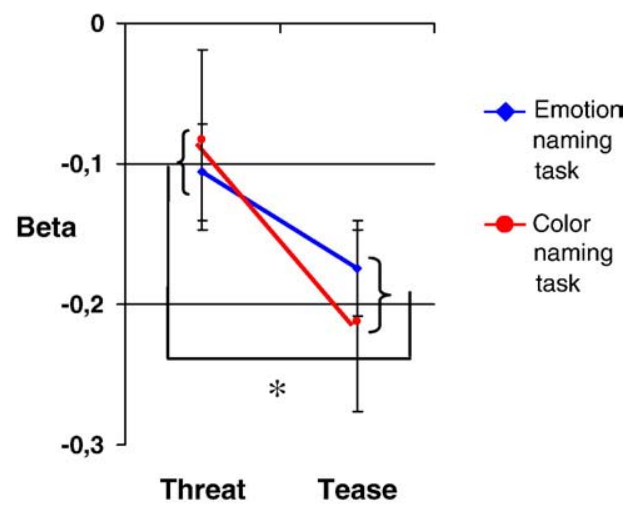

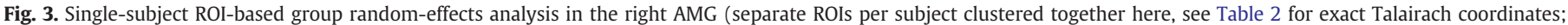
neurological convention). AMG is more responsive to threatening than teasing situations independent of task.

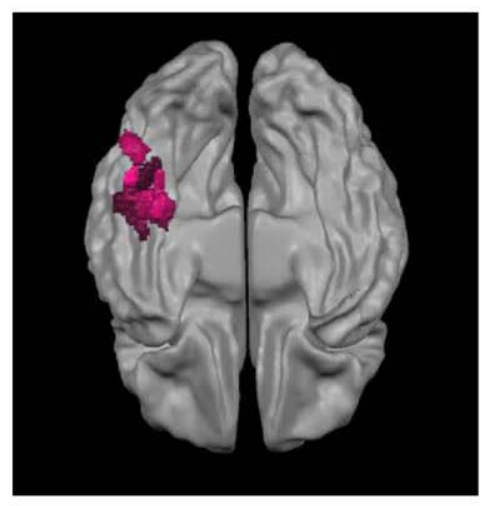

Left FG

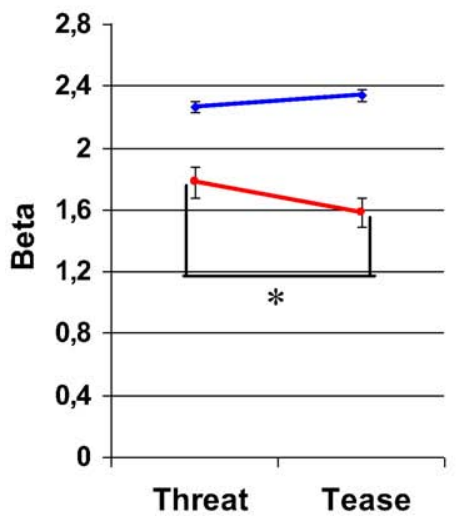

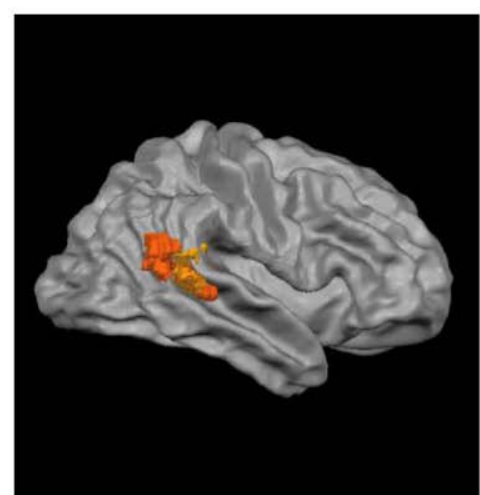

Right STS

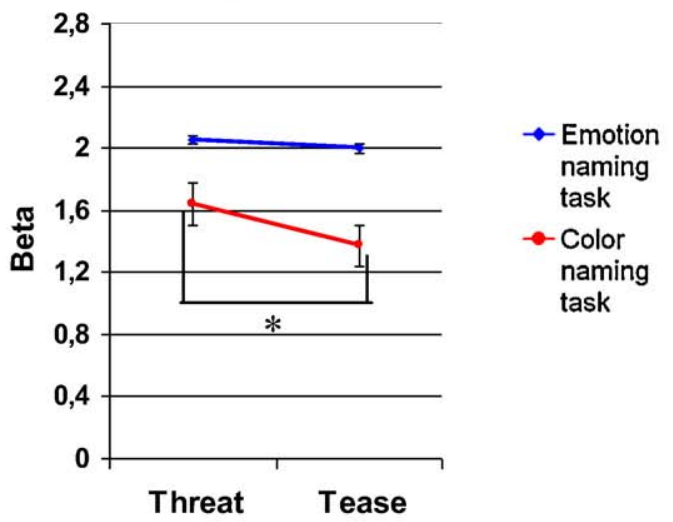

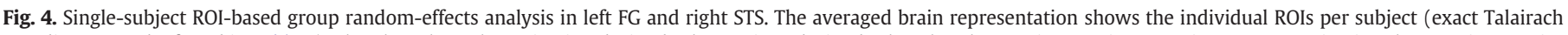

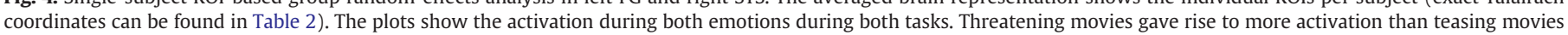
during the color naming task ( $p<.002$ for left FG and $p<.001$ for right STS). 
color naming task $(F(1,13)=25.651, p<.001, \eta \mathrm{p} 2=.66)$. $t$-Tests revealed bilaterally a difference between threatening and teasing in the color naming task (left: $t(13)=3.819, p=.002, d=.25$; right: $t$ $(13)=3.181, p=.007, d=.42)$.

Bilateral EBA-hMT+/V5 showed a main effect of emotion (more activation for threatening than teasing interactions) (left: $F(1,13)=$ 9.561, $p=.009, \eta \mathrm{p} 2=.42$; right: $F(1,13)=8.486, p=.012, \eta \mathrm{p} 2=.40)$ and a main effect for task (more activation during emotion than color naming task) (left: $F(1,13)=9.418, p=.009, \eta \mathrm{p} 2=.42$; right: $F(1,13)=11.201, p=.005, \eta \mathrm{p} 2=.46)$. Furthermore, right EBA showed a trend towards interaction $(F(1,13)=4.532, p=.053, \eta \mathrm{p} 2=.26)$. Therefore, we performed a $t$-test which revealed a difference between threat and tease in the color naming task $(t(13)=3.355, p=.005$, $d=.35$ ).

Bilateral STS showed a main effect of task: both show more activation during the emotion than color naming task (left: $F(1,5)=$ 10.718; $p=.022, \eta \mathrm{p} 2=.68$; right: $F(1,13)=40.576, p<.001, \eta \mathrm{p} 2=$ .79). Additionally, right STS showed an interaction $(F(1,13)=5.291$, $p=.042, \eta \mathrm{p} 2=.33)$. A $t$-test showed a difference between threatening and teasing in the color naming task $(t(13)=4.290, p=.001$, $d=.37)$.

\section{Whole-brain analysis}

An overview of the results of the whole-brain analysis is provided in Figs. 5 and 6 and Tables 3 to 5.

Regions showing an interaction between emotion and task. The whole-brain analysis showed an interaction between emotion and task in the cuneus, posterior cingulate cortex (PCC), left IFG (BA 45/ pars triangularis), left superior frontal gyrus (SFG), right anterior STS, and right middle occipital gyrus.

Activation related to observing either a threatening or a teasing situation independent of the task. The whole-brain analysis with contrast threatening vs. teasing movies revealed bilateral putamen and inferior occipital gyrus (IOG), IPL, hippocampus, and PCC in the left hemisphere. In the right hemisphere, hypothalamus/basal forebrain and TPJ were found. In addition, the surface-based analysis revealed PM, inferior temporal sulcus (ITS), and middle temporal gyrus (MTG) in the left hemisphere. In contrast, observing a teasing situation independent of the task only showed activation in right superior frontal gyrus (SFG).

Activation related to emotion naming independent of the emotion condition. Regions activated during the emotion naming task, independent whether it was a threatening or a teasing situation, were dorsomedial and dorsolateral PFC, OFC, IOG, TPJ, and ITS. In addition, only in the right hemisphere we found superior anterior TP, occipitotemporal sulcus, postcentral sulcus, and PCC. Additionally, the surface-based analysis also showed bilateral SFG and anterior STS in the right hemisphere.
Activation related to color naming independent of the emotion condition. Regions activated during the color naming task were dorsal postcentral gyrus, putamen, cuneus, and medial SFG. In the left hemisphere also superior temporal gyrus (STG) and dorsal precentral sulcus got activated, and in the right hemisphere, ventral precentral gyrus and supramarginal gyrus got activated.

\section{Discussion}

Our goal was to investigate the brain regions associated with witnessing an interaction between two people in which one person threatens the other and to assess whether explicitly paying attention to the situation makes a significant difference. Our major results are that right AMG is active in the attended as well as unattended threat condition while the body processing regions FG, EBA-hMT+/V5, and STS only for unattended threat. In contrast, left IFG responds specifically to threatening stimuli when attention is explicitly on the content of the movies. Right TPJ and hypothalamus, as known to be involved in processing moral violations, were found activated here for threatening situations. We discuss each aspect in turn.

\section{The automatic role of AMG for witnessing threatening interactions}

Our first hypotheses were about whether witnessing a threatening interaction between two people as an external observer will trigger AMG activity and whether this activation will persist when the observer is not paying attention to the nature of the situation but to an irrelevant detail. As predicted, our results clearly indicate that witnessing a threatening situation involving two other people is sufficient to trigger AMG. And, more importantly, this is the case for explicitly recognizing the threat and also when witnessing it while attention is turned away from what happens in the social interaction. This result is consistent with the notion that a threat stimulus may still be processed when no attention is paid to it. Previous studies have reported contradictory results concerning the automaticity of the AMG response to threatening stimuli. Some studies found AMG in attended as well as unattended trials (Vuilleumier et al., 2001), while other researchers argue that AMG is only observed when the task in the unattended condition is not difficult or not attention engaging enough and leaves resources available for processing the threatening stimuli (Pessoa et al., 2002), and still others believe the AMG actually prefers unattended threatening stimuli (Williams et al., 2005). It is worth noting that previous studies used still facial images, and of course, we cannot directly compare our task with those of other studies but our results are more in line with the view that the right AMG gets automatically activated for threatening stimuli, also when performing an attention-grabbing task. This result is in line with the finding that fearful bodies presented in the neglected left visual field of patients with right-sided parietal lesions were detected more often than when those bodies were happy (Tamietto et al., 2007). The finding that our effect was not bilateral is consistent with the

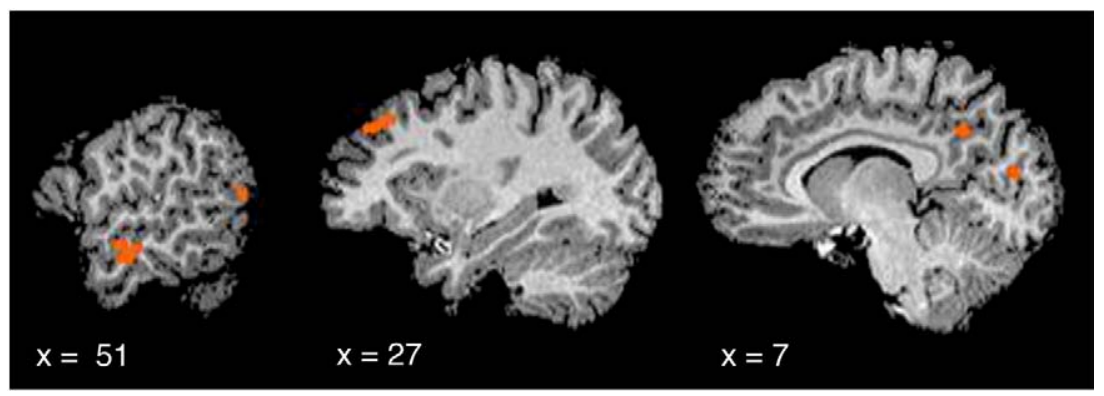

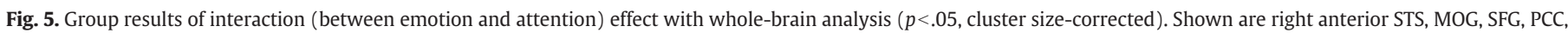
and cuneus. 
a

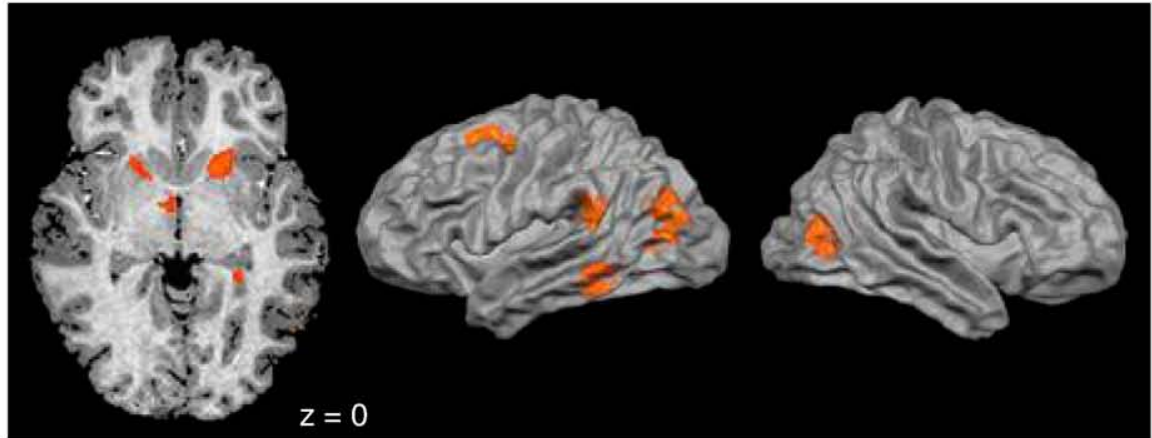

b
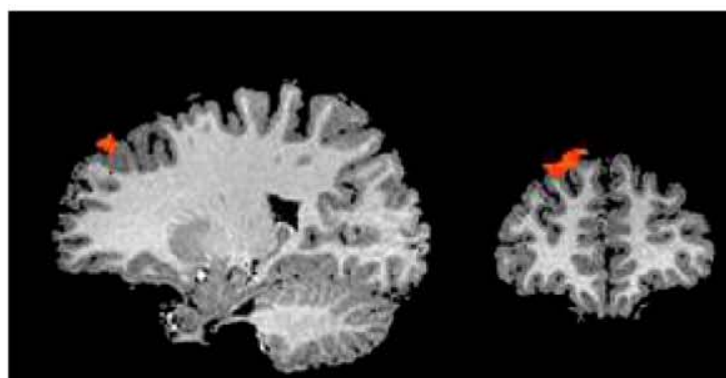

$x=18$

$y=42$

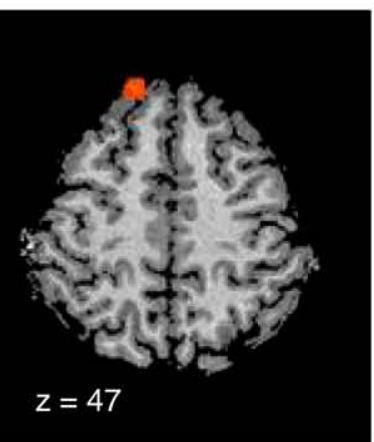

c

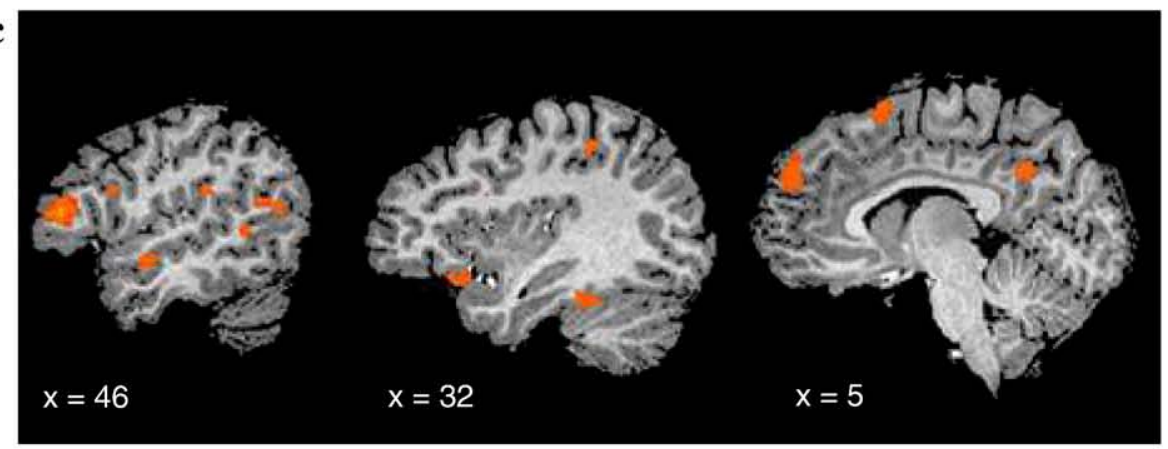

d

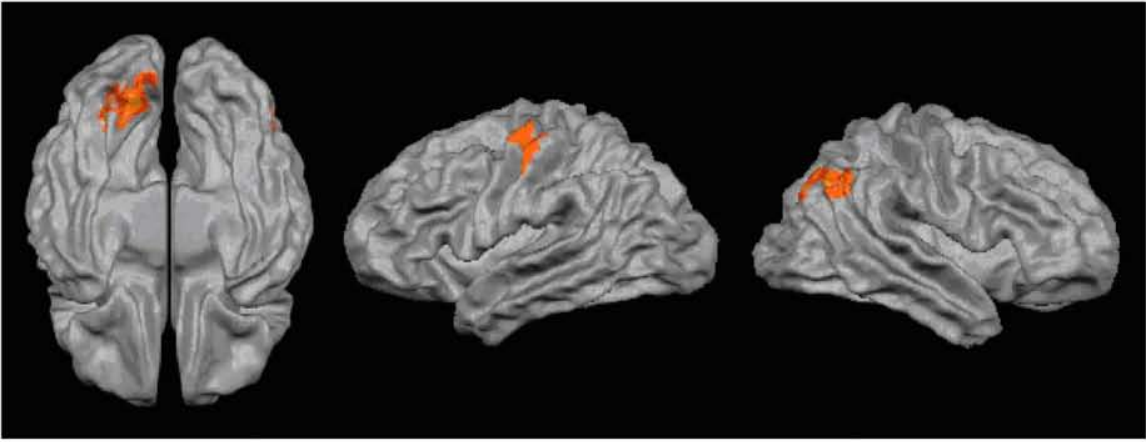

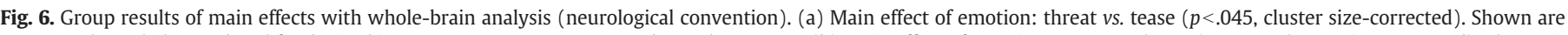

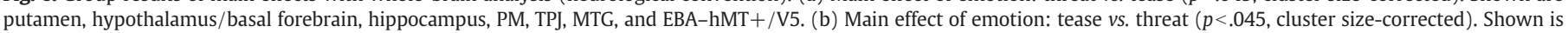

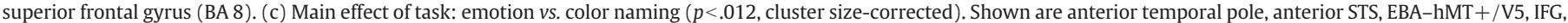

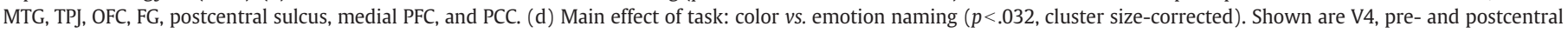
gyrus, and IPL.

literature (Williams et al., 2005), and additionally, right AMG has been shown to be involved in avoidance behavior in contrast to approach behavior in the left AMG (Davidson and Sutton, 1995).

During unattended threat there is more processing in body processing regions than during unattended tease

Besides right AMG, the body processing regions FG, EBA-hMT+/ V5, and STS also seem to be important for the processing of threat during inattention; they all show more activation for threatening than teasing situations during the color naming task. This was most clearly observed in left FG and right STS where an interaction was found, but there was also a trend in right FG and right EBA-hMT+/V5. Possibly, AMG detects the threat and passes this information on to these regions. Monkey data showed that the AMG also receives visual input from visual regions and the STS (Stefanacci and Amaral, 2000). Perhaps, this higher responsiveness in the body processing regions and right AMG during threatening than teasing situations leads to 
Table 3

Interaction between emotion and task as found with whole-brain ANOVA.

\begin{tabular}{llrrr}
\hline Interaction & & & & \\
\hline Region (BA) & Hemisphere & $x$ & $y$ & $z$ \\
\hline Cuneus (19) & $\mathrm{L}$ & -2 & -76 & 30 \\
Cuneus (18) & $\mathrm{R}$ & 5 & -77 & 14 \\
Posterior cingulate cortex (19) & $\mathrm{L}$ & -7 & -51 & 30 \\
Posterior cingulate cortex (31) & $\mathrm{R}$ & 11 & -51 & 32 \\
Inferior frontal gyrus (45) & $\mathrm{L}$ & -40 & 48 & -3 \\
Superior frontal gyrus (8/9) & $\mathrm{R}$ & 27 & 36 & 39 \\
Middle occipital gyrus (19) & $\mathrm{R}$ & 49 & -65 & 17 \\
Anterior superior temporal sulcus (38) & $\mathrm{R}$ & 49 & -12 & -11 \\
\hline
\end{tabular}

$p<.05$, cluster size-corrected.

heightened attention to the stimuli and better processing of the movies and therefore also to a better detection of the colored dots. This may explain the better behavioral performance of the participants during the threatening movies in the color naming task. This is also consistent with early attention cueing paradigms. When attention is already at the location where the dot is presented, subjects will be faster to detect it (Posner et al., 1978).

Nevertheless, there was more activation in those regions for both types of situations during the emotion than color naming task, which is in line with other studies (Grèzes et al., 2007; Pichon et al., 2007) and consistent with the finding that activation in regions involved in the perception of several classes of visual stimuli, in this case bodies, are reduced or even eliminated when participants are engaged in a separate task that requires focused attention (Vuilleumier et al., 2001; Chong et al., 2008). Why we do not find a difference between threatening and teasing movies during the emotion naming task could be explained by other studies that find attenuation of emotional responses during conscious evaluation, possibly mediated by right PFC (Hariri et al., 2000), which we actually do find to be activated more during the emotion than color naming task. Another possibility may be that a movie gives a participant more information than a still picture and because of the task demands, participants are actively trying to search for a threat in each movie or try to imagine each movie as a threat what already puts the activation at a higher level, while in the color naming task the participants are more naive.

\section{Seeing a threatening interaction triggers more action perception}

Besides STS, we were also interested in how the other regions of the action observation network reacted to our experimental conditions. Left IFG - more specifically, BA 45/pars triangularis - showed an interaction between emotion and task; it was more responsive for threatening than teasing situations during trials whereby attention was explicitly on the bodies, while this emotion effect disappeared during the other task (see Fig. 7). This indicates that the emotional

Table 4

Main effect of emotion as found with whole-brain ANOVA.

\begin{tabular}{llrrr}
\hline Region (BA) & Hemisphere & $x$ & $y$ & \multicolumn{1}{c}{$z$} \\
\hline Threat $>$ tease & & & & \\
$\quad$ Putamen & $\mathrm{L}$ & -18 & 10 & -2 \\
Putamen & $\mathrm{R}$ & 18 & 7 & -4 \\
Inferior occipital gyrus (19) & $\mathrm{L}$ & -45 & -63 & -12 \\
Inferior parietal lobe (19) & $\mathrm{L}$ & -40 & -69 & 36 \\
Posterior cingulate cortex (31) & $\mathrm{L}$ & -10 & -39 & 36 \\
Fusiform gyrus (20) & $\mathrm{L}$ & -40 & -38 & -14 \\
Hippocampus & $\mathrm{L}$ & -36 & -37 & -2 \\
Hypothalamus/basal forebrain & $\mathrm{R}$ & 4 & -6 & -7 \\
Temporoparietal junction (42) & $\mathrm{R}$ & 50 & -31 & 20 \\
Tease $>$ threat & & & & \\
Superior frontal gyrus (8) & $\mathrm{R}$ & 18 & 42 & 47 \\
\hline
\end{tabular}

$p<.045$, cluster size-corrected.
Table 5

Main effect of task as found with whole-brain ANOVA.

\begin{tabular}{llrrr}
\hline Region (BA) & Hemisphere & $x$ & $y$ & $z$ \\
\hline Emotion>color naming & & & & \\
Medial prefrontal cortex (6) & $\mathrm{L}$ & -4 & 19 & 57 \\
Medial prefrontal cortex (6) & $\mathrm{R}$ & 13 & 35 & 50 \\
Medial prefrontal cortex (6) & $\mathrm{R}$ & 5 & 12 & 58 \\
Medial prefrontal cortex (8) & $\mathrm{L}$ & -4 & 29 & 44 \\
Medial prefrontal cortex (10) & $\mathrm{R}$ & 8 & 52 & 31 \\
Inferior frontal gyrus (45) & $\mathrm{L}$ & -44 & 34 & 9 \\
Inferior frontal gyrus (44) & $\mathrm{R}$ & 48 & 31 & 15 \\
Inferior frontal sulcus (44) & $\mathrm{R}$ & 41 & 9 & 26 \\
Orbitofrontal gyrus (47) & $\mathrm{L}$ & -42 & 22 & 0 \\
Orbitofrontal gyrus (11) & $\mathrm{R}$ & 33 & 21 & -11 \\
Medial temporal gyrus (19) & $\mathrm{L}$ & -45 & -56 & 11 \\
Inferior temporal sulcus (19) & $\mathrm{R}$ & 51 & -48 & 7 \\
Temporoparietal junction (40) & $\mathrm{L}$ & -60 & -34 & 28 \\
Temporoparietal junction (42) & $\mathrm{R}$ & 50 & -31 & 25 \\
Fusiform gyrus (20) & $\mathrm{L}$ & -39 & -33 & -15 \\
Fusiform gyrus (20) & $\mathrm{R}$ & 35 & -34 & -17 \\
Temporal pole (38) & $\mathrm{R}$ & 45 & 10 & -19 \\
Postcentral sulcus (7) & $\mathrm{R}$ & 30 & -36 & 45 \\
Posterior cingulate cortex (31) & $\mathrm{R}$ & 5 & -51 & 33 \\
Posterior superior temporal gyrus (38) & $\mathrm{R}$ & 44 & -2 & -8 \\
Inferior occipital gyrus (18) & $\mathrm{R}$ & 40 & -61 & -5 \\
Middle occipital gyrus (19) & $\mathrm{R}$ & 45 & -59 & 17 \\
Color>emotion naming & & & & \\
Dorsal postcentral gyrus (7) & $\mathrm{L}$ & -49 & -14 & 49 \\
Dorsal postcentral sulcus (7) & $\mathrm{R}$ & 49 & -14 & 51 \\
Putamen & $\mathrm{L}$ & -24 & 2 & 5 \\
Putamen & $\mathrm{R}$ & -3 & -76 & 53 \\
Calcarine sulcus (18) & $\mathrm{L}$ & 5 & -72 & 13 \\
Cuneus (18) & $\mathrm{R}$ & -8 & -72 & -9 \\
Medial occipitotemporal gyrus (17) & $\mathrm{L}$ & -75 & -7 \\
Medial occipitotemporal gyrus (19) & $\mathrm{R}$ & -5 & 56 \\
Superior frontal gyrus (6) & $\mathrm{Bilateral}$ \\
Dorsal precentral gyrus (4) & $\mathrm{L}$ & -29 & 54 \\
Ventral precentral gyrus (6) & $\mathrm{R}$ & 24 \\
Supramarginal gyrus (39) & $\mathrm{R}$ & -4 & 45 \\
\hline
\end{tabular}

Emotion vs. color naming $(p<.012)$ and color $v$ s. emotion naming $(p<.032)$, both cluster size-corrected.

content in the dynamic bodies is not processed automatically in this region. Left IPL and left PM showed in general more activation for threatening than teasing situations. However, PM was more responsive during the color naming task. Apparently, when observers do not attend to the emotion, PM gets activated automatically. On the other hand, it could also be that the effect is caused by less activation during the emotion naming task as an inhibition of the natural tendency to respond as a consequence of depression of emotion-related areas during explicit judgment of emotion (Hariri et al., 2000).

TPJ also plays a role in biological movement and action perception (Allison et al., 2000). In this study, this area seems to have an emotional as well as an attentional role; in both hemispheres, it is activated more when attention is directed explicitly at the situation, while only the right side is also more responsive to threatening situations. Other studies have shown that this area is also part of a network related to attending to social stimuli that potentially are of behavioral significance (Corbetta and Shulman, 2002).

These findings lead us to suggest that threatening actions, although not directed at the observer, lead to more action perception.

\section{Moral dimension of recognizing social interactions}

We expected that making an overt decision about the situation would activate regions involved in moral cognition. Indeed, we did find anterior TP, TPJ, different foci in medial PFC and OFC. One interpretation consistent with the literature is that in the course of labeling the interaction, the participants are trying to figure out what the situation exactly means and are trying to ascribe intentions to the people involved. One may view this categorization as related to theory 

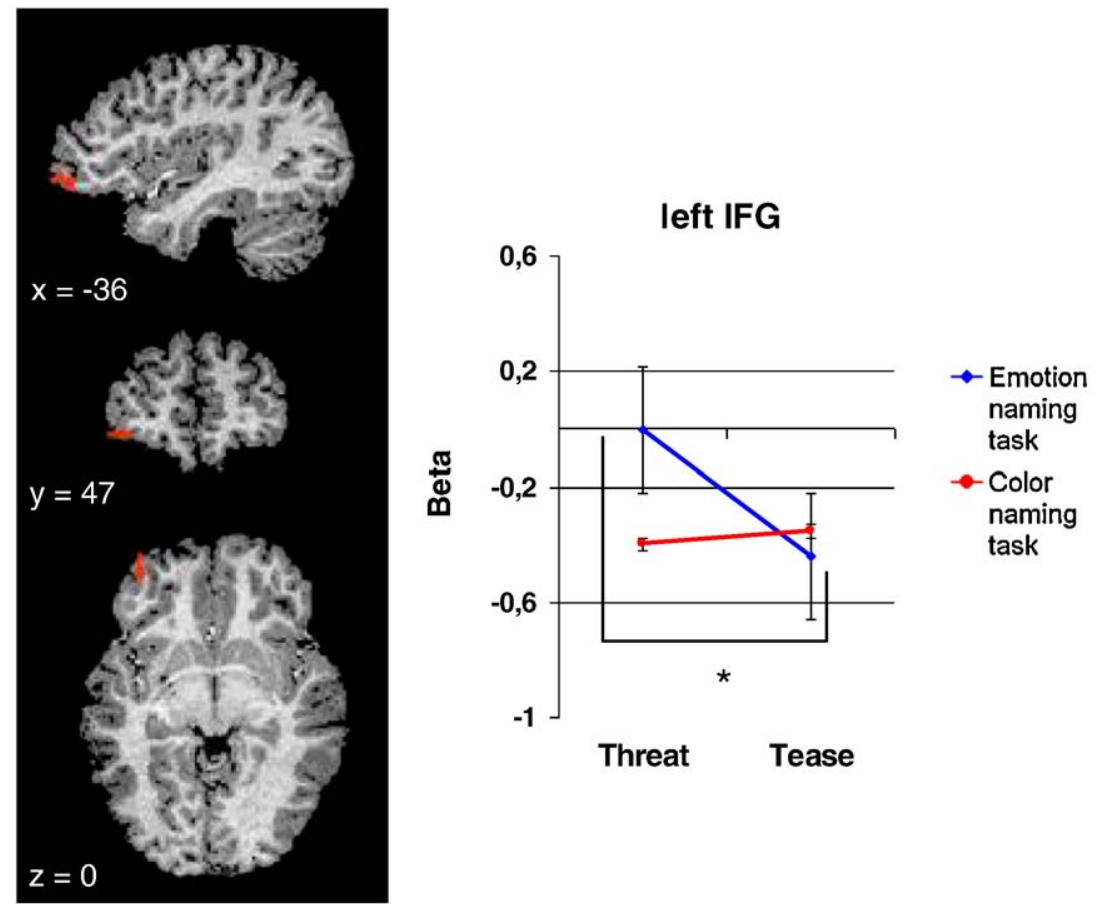

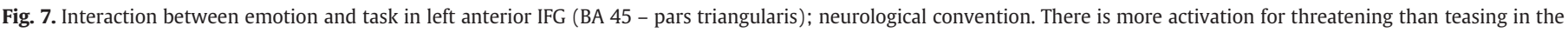
emotion naming task $(p<.004)$.

of mind tasks that activate the more anterior part of STS and TP (Castelli et al., 2000; Gallagher et al., 2000; Saxe and Kanwisher, 2003), two regions that we also found activated in the right hemisphere for the contrast emotion vs. color naming task. Furthermore, both regions are also involved in retrieval of autobiographical memories (Maguire et al., 2000), information which may be used to understand the actions of the people in the movies. Sensory and limbic information is send to the TP and patients with a lesion in this region show impairments in naming human actions (Lu et al., 2002). However, other studies have also reported that TP is involved in processing emotional actions with both static and dynamic stimuli (Grèzes et al., 2007), but we do not find this region to be activated more for threatening vs. teasing interactions in this study. However, teasing is not exactly the same as being emotional neutral, so it is not surprising that the results do not show a difference here.

Using verbal statements, Moll et al. (2008) found anterior PFC, hypothalamus, and anterior cingulate cortex responsive during compassion, and also anterior PFC, hypothalamus, and OFC during indignation, both moral feelings that our stimuli may trigger. Among these regions, we found PFC and OFC to be activated more during the emotion naming task for both threatening and teasing situations. Only hypothalamus was differentially activated for threatening $v s$. teasing stimuli.

TPJ was already mentioned above in relation to action perception. Besides that, TPJ activity has also been reported in combination with left FG in a study that compared brain activations for hearing verbal stories about intentional violations of social norms with stories about normal behaviour (Berthoz et al., 2002). Both regions are also found activated in our study for threatening situations, so the TPJ activation may also be triggered by the knowledge that stealing a handbag is an intentional violation, instead of being mere action perception.

\section{Activation related to observing a threatening situation independent} of the task

We already saw heightened STS and left PM activation, as being part of the action observation network, to a threatening situation independent of task. Seeing a threatening situation may prompt a reaction in the observer and trigger motor preparation (de Gelder et al., 2004; Hoshi and Tanji, 2004). Another area involved in this is the hypothalamus. The hypothalamus has a direct connection to the brainstem and autonomic spinal centers, that can increase, i.e., heart rate and breathing, all necessary to prepare the body for action (Barbas et al., 2003). In humans, electrical stimulation of the hypothalamus has been shown to evoke aggressive reactions (Bejjani et al., 2002). These findings support the idea that the PM activation found here goes beyond mere action observation and reflects activity related to automatically triggered preparation for action in reaction to the threatening situation. Similarly, more responsiveness in bilateral putamen could be related to a higher motor response during threatening situations (de Gelder et al., 2004).

The activation in hippocampus in relation to threatening situations is in line with previous research. In a study that used emotional and neutral faces whereby participants had to perform either an emotion or an age discrimination task, AMG and left hippocampus activation was found for the former task (Gur et al., 2002).

One might argue that the differential activation between teasing and threatening movies reflects ambiguity inherent to the teasing situation possibly therefore requiring more decoding resources. However, the behavioral data do not support this since participants are equally accurate in explicitly judging the threatening and teasing movies. Furthermore, the threatening movies trigger activity in many areas, while for teasing ones only right SFG gets activated. This region has not been found in studies focusing on ambiguity (e.g., Nomura et al., 2003; Hsu et al., 2005; Jenkins and Mitchell, 2009; Winston et al., 2003; Simmons et al., 2006), where mostly medial PFC has been found.

Activation related to attending to the situation independent of the emotion

It may be the case that participants judge the situation they observe in the video on the basis of past experiences. This may explain the simultaneous activation of TP, PCC, and MPFC which have been 
related to memory retrieval (Vincent et al., 2006). These regions could work in tandem with frontal areas such as IFG and dmPFC to appraise the situation and extract the right information (Kober et al., 2008). In the monkey, mPFC and OFC have, also via the AMG, strong connections going through the hypothalamus to the brainstem and efferent autonomic structures (Barbas et al., 2003). Possibly, the elevated activation here indicates a heightened state of alertness to be able to project information further into the spinal system once necessary.

But it could also be that dmPFC gets activated purely by paying attention to the social interaction. Namely, a study by Iacoboni et al. (2004) reported heightened activation in this region and in medial parietal areas when participants watched movies of everyday social interactions compared either to rest or to movies showing an individual in the same context. Also because these activities occurred together with activation in STS, IFG, and FG, this led the authors to suggest that dmPFC and medial parietal areas are involved in the processing of social relations. Since we also found all of these regions activated - together with PCC - when participants had to focus on the meaning of the social interaction, our study seems to support this idea.

Activation related to inattentively observing an interaction independent of the emotion

When participants had to pay attention to the colored dots in the task in comparison with paying attention to the situation, we found more activation in regions within the occipital lobe which includes possibly area V4, an area important for color perception (Zeki et al., 1991). Lesions in this area cause difficulty with allocating visual attention or it can result in achromatopsia (Zeki et al., 1991; Gallant et al., 2000). Since the movies were in black/white, searching for the dots was mainly searching for colors, therefore the finding that V4 was activated for this contrast seems very intuitive. Enhancement of these sensory features by attention might help in target detection.

Since the behavioral results show that participants performed the color naming task better than the emotion naming task, more activation in left precentral gyrus could be related to the certainty of the participants, leading to a stronger right button press for the former task.

\section{Conclusion}

We showed that right AMG is involved in witnessing threatening situations the observer is not part of, also when not actually paying attention to the situation. This AMG activation during the color naming task co-occurred with activations in body processing regions FG, EBA-hMT+/V5, and STS.

Regions involved in action perception (IFG and TPJ) responded more when the interaction was threatening and when attention was directed explicitly to it. Also left IPL showed a heightened response to threatening situations. Regions more related to motor preparation than action observation, left PM and putamen, were also shown to be more responsive for threatening than teasing movies.

As expected, regions involved in moral cognition (anterior TP, medial PFC, OFC, and TPJ) were activated when an overt decision had to be made about the situation. But PFC and OFC were not activated more for threatening situations representing moral violations as one might have expected. However, TPJ and hypothalamus were activated in that condition.

In focusing on interactions, our study adds significantly to previous research using isolated faces or bodies. Taken together, our results show which regions are responsible for the ability of people to detect a situation they are not involved in themselves as a threat and that they can do so even though they are not explicitly paying attention to the situation. Future studies need to focus on the timing of activation and the connectivity between the limbic system, body processing areas, and higher cortical regions.

\section{Acknowledgments}

This project was funded in part by EU project COBOL (FDP6-NEST043403).

We thank the reviewers for their useful comments.

\section{References}

Adolphs, R., 2003. Cognitive neuroscience of human social behaviour. Nat. Rev., Neurosci. 4, 165-178.

Allison, T., Puce, A., McCarthy, G., 2000. Social perception from visual cues: role of the STS region. Trends Cogn. Sci. 4, 267-278.

Barbas, H., Saha, S., Rempel-Clower, N., Ghashghaei, T., 2003. Serial pathways from primate prefrontal cortex to autonomic areas may influence emotional expression. BMC Neurosci. 4, 25.

Beauchamp, M.S., Lee, K.E., Haxby, J.V., Martin, A., 2003. FMRI responses to video and point-light displays of moving humans and manipulable objects. J. Cogn. Neurosci. 15, 991-1001.

Bejjani, B.P., Houeto, J.L., Hariz, M., Yelnik, J., Mesnage, V., Bonnet, A.M., Pidoux, B. Dormont, D., Cornu, P., Agid, Y., 2002. Aggressive behavior induced by intraoperative stimulation in the triangle of Sano. Neurology 59, 1425-1427.

Berthoz, S., Armony, J.L., Blair, R.J., Dolan, R.J., 2002. An fMRI study of intentional and unintentional (embarrassing) violations of social norms. Brain 125, 1696-1708.

Bonda, E., Petrides, M., Ostry, D., Evans, A., 1996. Specific involvement of human parietal systems and the amygdala in the perception of biological motion. J. Neurosci. 16 3737-3744.

Brass, M., Bekkering, H., Prinz, W., 2001. Movement observation affects movement execution in a simple response task. Acta Psychol. (Amst) 106, 3-22.

Castelli, F., Happe, F., Frith, U., Frith, C., 2000. Movement and mind: a functional imaging study of perception and interpretation of complex intentional movement patterns. Neurolmage 12, 314-325.

Chong, T.T., Williams, M.A., Cunnington, R., Mattingley, J.B., 2008. Selective attention modulates inferior frontal gyrus activity during action observation. Neurolmage 40 298-307.

Corbetta, M., Shulman, G.L., 2002. Control of goal-directed and stimulus-driven attention in the brain. Nat. Rev., Neurosci. 3, 201-215.

Davidson, R.J., Sutton, S.K., 1995. Affective neuroscience: the emergence of a discipline Curr. Opin. Neurobiol. 5, 217-224.

de Gelder, B., 2006. Towards the neurobiology of emotional body language. Nat. Rev., Neurosci. 7, 242-249.

de Gelder, B., Snyder, J., Greve, D., Gerard, G., Hadjikhani, N., 2004. Fear fosters flight: a mechanism for fear contagion when perceiving emotion expressed by a whole body. Proc. Natl. Acad. Sci. Online (US) 101, 16701-16706.

Dolan, R.J., Vuilleumier, P., 2003. Amygdala automaticity in emotional processing. Ann. N.Y. Acad. Sci. 985, 348-355.

Forman, S.D., Cohen, J.D., Fitzgerald, M., Eddy, W.F., Mintun, M.A., Noll, D.C., 1995. Improved assessment of significant activation in functional magnetic resonance imaging (fMRI): use of a cluster-size threshold. Magn. Reson. Med. 33, 636-647.

Gallagher, H.L., Happe, F., Brunswick, N., Fletcher, P.C., Frith, U., Frith, C.D., 2000 Reading the mind in cartoons and stories: an fMRI study of 'theory of mind' in verbal and nonverbal tasks. Neuropsychologia 38, 11-21.

Gallant, J.L., Shoup, R.E., Mazer, J.A., 2000. A human extrastriate area functionally homologous to macaque V4. Neuron 27, 227-235.

Goebel, R., Esposito, F., Formisano, E., 2006. Analysis of functional image analysis contest (FIAC) data with BrainVoyager QX: from single-subject to cortically aligned group general linear model analysis and self-organizing group independent component analysis. Hum. Brain Mapp. 27, 392-401.

Grèzes, J., Pichon, S., de Gelder, B., 2007. Perceiving fear in dynamic body expressions NeuroImage 35, 959-967.

Grosbras, M.H., Paus, T., 2006. Brain networks involved in viewing angry hands or faces Cereb. Cortex 16, 1087-1096.

Gur, R.C., Schroeder, L., Turner, T., McGrath, C., Chan, R.M., Turetsky, B.I., Alsop, D. Maldjian, J., Gur, R.E., 2002. Brain activation during facial emotion processing. Neurolmage 16, 651-662.

Hadjikhani, N., de Gelder, B., 2003. Seeing fearful body expressions activates the fusiform cortex and amygdala. Curr. Biol. 13, 2201-2205.

Hariri, A.R., Bookheimer, S.Y., Mazziotta, J.C., 2000. Modulating emotional responses: effects of a neocortical network on the limbic system. NeuroReport 11 (1), 43-48.

Hoshi, E., Tanji, J., 2004. Functional specialization in dorsal and ventral premotor areas Prog. Brain Res. 143, 507-511.

Hsu, M., Bhatt, M., Adolphs, R., Tranel, D., Camerer, C.F., 2005. Neural systems responding to degrees of uncertainty in human decision-making. Science 310 (5754), 1680-1683.

Iacoboni, M., Lieberman, M.D., Knowlton, B.J., Molnar-Szakacs, I., Moritz, M., Throop, C.J., Fiske, A.P., 2004. Watching social interactions produces dorsomedial prefrontal and medial parietal BOLD fMRI signal increases compared to a resting baseline. Neurolmage 21, 1167-1173.

Jenkins, A.C., Mitchell, J.P., 2009. Mentalizing under uncertainty: dissociated neural responses to ambiguous and unambiguous mental state inferences. Cereb. Cortex. 
Kober, H., Barrett, L.F., Joseph, J., Bliss-Moreau, E., Lindquist, K., Wager, T.D., 2008. Functional grouping and cortical-subcortical interactions in emotion: a metaanalysis of neuroimaging studies. Neurolmage 42, 998-1031.

LeDoux, J.E., 1992. Brain mechanisms of emotion and emotional learning. Curr. Opin. Neurobiol. 2, 191-197.

Lu, L.H., Crosson, B., Nadeau, S.E., Heilman, K.M., Gonzalez-Rothi, L.J., Raymer, A., Gilmore, R.L., Bauer, R.M., Roper, S.N., 2002. Category-specific naming deficits for objects and actions: semantic attribute and grammatical role hypotheses. Neuropsychologia 40, 1608-1621.

Maguire, E.A., Mummery, C.J., Buchel, C., 2000. Patterns of hippocampal-cortical interaction dissociate temporal lobe memory subsystems. Hippocampus 10 475-482.

Moll, J., De Oliveira-Souza, R., Zahn, R., 2008. The neural basis of moral cognition: sentiments, concepts, and values. Ann. N.Y. Acad. Sci. 1124, 161-180.

Nomura, M., Iidaka, T., Kakehi, K., Tsukiura, T., Hasegawa, T., Maeda, Y., et al., 2003. Frontal lobe networks for effective processing of ambiguously expressed emotions in humans. Neurosci. Lett. 348 (2), 113-116.

Pessoa, L., Japee, S., Ungerleider, L.G., 2005. Visual awareness and the detection of fearful faces. Emotion 5, 243-247.

Pessoa, L., McKenna, M., Gutierrez, E., Ungerleider, L.G., 2002. Neural processing of emotional faces requires attention. Proc. Natl. Acad. Sci. U. S. A. 99, $11458-11463$.

Pichon, S., De Gelder, B., Grèzes, J., 2007. Emotional modulation of visual and motor areas by still and dynamic body expressions of anger. Soc. Neurosci. 3, 199-212.

Posner, M.I., Nissen, M.J., Ogden, W.C., 1978. Attended and unattended processing modes: the role for spatial location. In: Pick, HL, Saltzman, EJ (Eds.), 1978 Modes of Perceiving and Processing Information. Erlbaum, Hillsdale, NJ, pp. 137-157.
Saxe, R., Kanwisher, N., 2003. People thinking about thinking people. The role of the temporo-parietal junction in "theory of mind". Neurolmage 19, 1835-1842.

Simmons, A., Stein, M.B., Matthews, S.C., Feinstein, J.S., Paulus, M.P., 2006. Affective ambiguity for a group recruits ventromedial prefrontal cortex. NeuroImage 29 (2), 655-661.

Stefanacci, L., Amaral, D.G., 2000. Topographic organization of cortical inputs to the lateral nucleus of the macaque monkey amygdala: a retrograde tracing study. J. Comp. Neurol. 421, 52-79.

Tamietto, M., Geminiani, G., Genero, R., de Gelder, B., 2007. Seeing fearful body language overcomes attentional deficits in patients with neglect. J. Cogn. Neurosci. 19 (3), 445-454.

Vincent, J.L., Snyder, A.Z., Fox, M.D., Shannon, B.J., Andrews, J.R., Raichle, M.E., Buckner, R.L., 2006. Coherent spontaneous activity identifies a hippocampal-parietal memory network. J. Neurophysiol. 96, 3517-3531.

Vuilleumier, P. Armony, J.L. Driver, J. Dolan, R. 2001. Effects of attention and emotion on face processing in the human brain: an event-related fMRI study. Neuron 30, 829-841.

Williams, M.A., McGlone, F., Abbott, D.F., Mattingley, J.B., 2005. Differential amygdala responses to happy and fearful facial expressions depend on selective attention. NeuroImage 24, 417-425.

Winston, J.S., O'Doherty, J., Dolan, R.J., 2003. Common and distinct neural responses during direct and incidental processing of multiple facial emotions. Neurolmage 20 (1), 84-97.

Zahn, R., Moll, J., Paiva, M., Garrido, G., Krueger, F., Huey, E.D., Grafman, J., 2008. The neural basis of human social values: evidence from functional MRI. Cereb. Cortex.

Zeki, S., Watson, J.D., Lueck, C.J., Friston, K.J., Kennard, C., Frackowiak, R.S., 1991. A direct demonstration of functional specialization in human visual cortex. J. Neurosci. 11, 641-649. 